\title{
Metrosexual Identification: Gender Identity And Beauty-Related Behaviors
}

Aurathai Lertwannawit, Ph.D., Suan Dusit Rajabhat University, Thailand

Nak Gulid, Ph.D., Srinakharinwirot University, Thailand

\begin{abstract}
This paper identifies the term metrosexual using the Bem sex role inventory and appearancerelated variables, i.e. self monitoring, status consumption, fashion consciousness, cloth concern, and body self-relation. A quantitative study was performed using 263 heterosexual metropolitan men from Bangkok. An ANOVA was used to test the hypotheses. The results indicate that metrosexuals can be described by their gender identity having a high score for femininity, which characterizes feminine and androgynous personality traits. These two groups have high scores for all appearance-related variables, especially self monitoring and body self-relation.
\end{abstract}

Keywords: Metrosexual, Gender Identity, Appearance-related Variables, Self Monitoring, Status Consumption, Fashion Consciousness, Cloth Concern, Body Self-Relation

\section{INTRODUCTION}

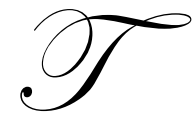

oday, as men play a bigger and more active role in modern consumerism (Bakewell et al., 2006) they look for an identity construction which can be achieved through a particular style of dress, body care, image and look (Bakewell et al., 2006; Katz \& Farrow, 2000; Miller et al., 2000). Appearance-related behavior has increased tremendously and is intruding on traditional masculine consumption behavior (Holt \& Thompson, 2004). This behavior is driven by the need for the creation and attainment of a desired self-image, identity and self-concept. The trend for Thai men to spend resources, both fiscal, temporal, and personal on their physical look and appearance began in the late 1990s in parallel with the popularity of David Beckham in Thailand. The emergence of the metrosexual poses new challenges for studies of masculinity in consumer behavior in Thailand, where traditional male identities, including such characteristics as hardness and strength, have always been representative of masculinity in Thailand. This shift not only effects change in Thai masculine values, it also effects core cultural change in the country. Consequently, to understand the newly emerging market segment, this research is undertaken with the objective of delving into the identification of the metrosexuals using the gender identification method of Bem's (1981b) gender schema theory, which reflects the appearance-related variables of a) self monitoring, b) status consumption, c) fashion consciousness, d) cloth concern, and e) body self-relation.

\section{LITERATURE REVIEWS}

\section{Metrosexual: Changing Masculinity}

In 1994, Mark Simpson defined "metrosexual" in The Independent: "Metrosexual man, the single young man with a high disposable income, living or working in the city (because that's where all the best shops are), is perhaps the most promising consumer market of the decade." The metrosexual is consistently configured as a heterosexual metropolitan man who spends time and effort on his appearance. The values of the hedonistic, stylecentred metrosexual lifestyle place little emphasis on long-term relationships or parenting. The metrosexual may well represent a more attractive, or compatible version of masculinity for some women, in that metrosexuals are better groomed and dressed than most other men and have a penchant for so-called "feminine" interests and activities, such as shopping, cooking and the arts. In addition, this soft version of masculinity may arguably be more receptive to pro-feminist values than more traditional "hard" masculinity. The metrosexual may represent a new "feminized" masculinity; however, it maintains an essential distinction between the biological sexes. The metrosexual has contributed to the blurring of the categories of heterosexuality, homosexuality, and bisexuality 
within the category of men; however, it has not had the same effect on the categories of men and women (Blazina \& Watkins, 2000).

\section{Gender Identity}

Gender Identity has been referred to as the bipolarity of individual traits comprising masculinity and femininity (Spence, 1984). Some psychologies believe that masculinity and femininity may vary within an individual regardless of biological sex (Gill et al., 1987). Bem (1974) proposed that a person can be masculine, feminine, undifferentiated or "androgynous" as an indicator of the difference between his or her endorsement of masculine and feminine personality characteristics. The term androgynous has been used to describe individuals who possess masculine and feminine traits in balanced proportion (Bem, 1974). There is numerous research focused on the effects of gender identity on consumer behavior, including leisure activities, shopping behavior and impulse buying (Dittmar et al., 1994; Palan, 2001). There are two main competing gender identity instruments: the Bem Sex Role Inventory (BSRI) and the Personal Attributes Questionnaire (PAQ). Spence (2006) compared BSRI and PAQ measurement and concluded that both are similar in content and that the parallel masculinity and femininity scales are substantially correlated. In addition, the instruments can both measure three areas - self-esteem, sex-role attitudes, and gender-schematic processing.

\section{RESEARCH OBJECTIVES} questions:

This paper, reporting descriptive research, seeks to provide tentative answers to the following basic

a) What is the gender identity of heterosexual metropolitan men?

b) In order to identify metrosexuals, how different are appearance-related variable scores among heterosexual metropolitan men?

\section{CONCEPTUAL MODEL AND HYPOTHESES RELATIONSHIP}

\section{Conceptual Model}

"Metrosexual" terminology has been used by marketing practitioners without academic empirical study to confirm the femininity traits in metropolitan men which affect their appearance-related behaviors. Consequently, this research proposes that metrosexuals can be identified by their gender identity. And the higher they score for femininity, the greater the different personality traits will be reflected in their appearance-related variables. In other words, this paper proposes that metrosexuals can be identified by feminine and androgynous personality traits and high levels of appearance-related attitudes. The conceptual model for this paper is depicted in Figure 1.

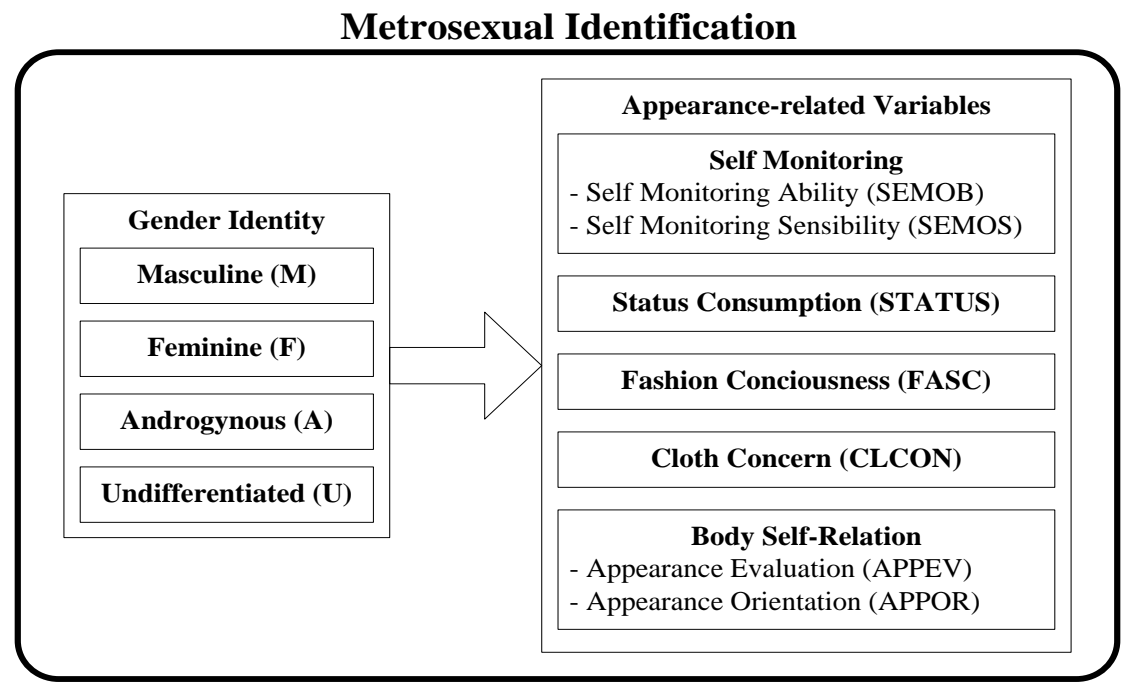

Figure 1 Concentual Model 


\section{Hypotheses}

According to the conceptual model in Figure 1, the alternate hypotheses are as follows:

H1: Significant differences will exist in masculinity and femininity among the different gender identities of heterosexual metropolitan men.

H2: Significant differences will exist between the different gender identities of heterosexual metropolitan men as measured by appearance-related variables: a) self monitoring, b) status consumption, c) fashion consciousness, d) cloth concern, and e) body self-relation.

\section{RESEARCH METHODOLOGY}

The study used quantitative methodology. A survey was conducted to collect the data. The following explains the research design used for the data collection and testing of the hypotheses stated above.

\section{Sample}

In this study the sample contained heterosexual males, aged between 20 and 50 years, with an average monthly income equal to or higher than 20,000 baht (570 US dollars), living in Bangkok, the capital city of Thailand. Purposive sampling was used in collecting the data. Two screening questions were asked before the questionnaire was distributed. The questions were a) what is your average monthly income? and $b$ ) What is your sexual preference (homosexual, heterosexual, bisexual)? The total sample size was 263 persons.

\section{Questionnaire Development}

The questionnaire was developed based on standard item scales. Conceptual equivalence is a concern when translating Western-developed instruments into Thai for Thai respondents. Translation and back-translation were independently performed by two bilingual professionals. The incongruities between the two versions were carefully examined and resolved.

Gender Identity (GI) For clarity and conciseness, the short version of the Bem Sex Role Inventory (BSRISF) (Bem, 1981a, 1981b) was used for data collection. This test comprised 30 items used to investigate masculinity and femininity. Respondents were asked to rate themselves as to how well each adjective described them on seven-point Likert scale with (1) being "never" and (7) being "always". Masculinity and femininity were measured by ten items. Internal consistency and reliability were generally considered acceptable and details are listed in Table 1.

Table 1 Factor Analysis of Masculinity and Femininity Items

\begin{tabular}{|l|c|c|c|l|c|c|c|}
\hline Masculinity & Mean & S.D. & $\begin{array}{c}\text { Factor } \\
\text { loading }\end{array}$ & Femininity & Mean & S.D. & $\begin{array}{c}\text { Factor } \\
\text { loading }\end{array}$ \\
\hline Defend my own beliefs & 4.96 & 1.320 & .714 & Affectionate & 4.73 & 1.161 & .400 \\
\hline Independent & 5.52 & 1.194 & .639 & Sympathetic & 5.19 & 1.218 & .687 \\
\hline Assertive & 5.31 & 1.248 & .741 & Sensitive to needs of others & 3.78 & 1.687 & .469 \\
\hline Strong personality & 5.44 & 1.157 & .624 & Understanding & 4.96 & 1.118 & .717 \\
\hline Forceful & 2.86 & 1.611 & .396 & Compassionate & 5.42 & 1.119 & .750 \\
\hline Have leadership qualities & 5.30 & 1.307 & .757 & Eager to soothe hurt feelings & 4.62 & 1.422 & .787 \\
\hline Willing to take risks & 4.83 & 1.536 & .632 & Warm & 5.14 & 1.200 & .678 \\
\hline Dominant & 3.57 & 1.791 & .634 & Tender & 4.46 & 1.608 & .742 \\
\hline Willing to take a stand & 5.75 & .983 & .656 & Love children & 4.61 & 1.476 & .500 \\
\hline Aggressive & 2.78 & 1.577 & .376 & Gentle & 4.24 & 1.692 & .726 \\
\hline Average score & 4.72 & .888 & & Average score & 4.63 & .850 & \\
\hline Eigenvalue & & 3.960 & Eigenvalue & & 4.336 \\
\hline \% of Variance & & 39.597 & \% of Variance & & 43.357 \\
\hline Cumulative \% & .826 & Kaiser-Meyer-Olkin coefficient & & 43.357 \\
\hline Kaiser-Meyer-Olkin coefficient & .8133 & Cronbach Alpha & .817 \\
\hline Cronbach Alpha & & &
\end{tabular}


Appearance-related Variables (APVs). The standard scale of five consumer variables relating to appearance issues was selected. Respondents were asked to state the extent of individual congruence with each statement. Items were measured on a seven-point Likert scale in which the respondent indicated "the degree to which each of the statements described him" - "strongly disagree (1)", "disagree (2)", "somewhat disagree (3)", neither agree nor disagree (4)", "somewhat agree (5)", "agree (6)", and "strongly agree (7)". Internal consistency and reliability were generally considered acceptable and details are listed in Table 2.

Self monitoring (SELF) was developed by O'Cass (2000) and comprises two dimensions, self-monitoring ability (SEMOB) and self-monitoring sensitivity (SEMOS). It refers to the degree to which a person observes and controls their expressive behavior and self-presentation in accordance with social cues (Gould, 1993; Snyder, 1974).

Status Consumption (STATUS) was developed by Eastman et al. (1999). It refers to an interest in consuming for status, which involves a desire for status and conspicuous consumption.

Fashion Consciousness (FASC) was developed by Shim and Gehrt (1996) and refers to the degree of involvement an individual has with the latest fashion clothing styles (Nam et al., 2006), and the desire for up-to-date clothing styles and frequent changes to one's wardrobe (Mitchell \& Walsh, 2004; Shim \& Gehrt, 1996; Walsh et al., 2001; Wells, 1971).

Cloth Concern (CLCON) was developed by Netemeyer et al. (1995). It describes the importance of clothes in personal appearance, measuring the degree of one's willingness to invest time, money and effort in being more attentive in clothing choices.

The Multidimensional Body Self-relations Questionnaire (MBSRQ) is comprised of a two-dimensional appearance evaluation scale (APPEV) and an appearance orientation (APPOR) scale. It was developed by Corcoran and Fischer (2000).

Table 2 Descriptive Statistics for APVs

\begin{tabular}{|l|c|c|c|c|}
\hline APVs & Mean & S.D. & Cronbach Alpha & $\begin{array}{c}\text { \# of items } \\
\text { (original / current) }\end{array}$ \\
\hline SEMOB & 5.00 & .823 & 0.7692 & $6 / 4$ \\
\hline SEMOS & 4.96 & .881 & 0.8479 & $6 / 6$ \\
\hline STATUS & 4.05 & 1.338 & 0.9045 & $5 / 4$ \\
\hline FASC & 4.22 & 1.385 & 0.9045 & $4 / 4$ \\
\hline CLCON & 4.46 & 1.018 & 08734 & $7 / 7$ \\
\hline APPEV & 4.43 & 1.112 & 0.8694 & $7 / 5$ \\
\hline APPOR & 4.80 & .968 & 0.8480 & $10 / 6$ \\
\hline
\end{tabular}

\section{RESEARCH RESULTS}

\section{Respondent Profile}

Respondents were all heterosexual metropolitan men with an average age of 39 years, who have lived in Bangkok for an average of 27 years with average monthly income of around 65,000 Baht (or 1,857 US dollar). Their average percentage spend per month is $5 \%$ for facial products, $7 \%$ for body care products, $4 \%$ for hair care products, $10 \%$ for personal attire, $11 \%$ for hi-tech products, $10 \%$ for wellness-related products and services, and $10 \%$ for relaxation products and services. $54 \%$ are single, with sub-classifications of $32 \%$ single, $5 \%$ looking for love, $16 \%$ in a relationship, $2 \%$ divorced, and $2 \%$ separated.

\section{Hypotheses Testing}

Hypothesis 1: Significant differences will exist in masculinity and femininity among the different gender identities of heterosexual metropolitan men. 
Scores on the BSRISF are purported to measure the respondent's degree of masculinity, femininity, androgyny or undifferentiated sex-role identity. Subjects who scored masculinity items higher than 4.9 and femininity items lower than 4.9 are considered to score highly for masculine (M), and vice versa for feminine (F). Subjects scoring lower than 4.9 in both masculinity and femininity are labeled undifferentiated (U), whereas those scoring higher than 4.9 in both are considered androgynous (A). Consequently, the 263 respondents were classified into four groups: masculinity, femininity, androgynous, and undifferentiated. Table 2 indicates that there are significant differences between masculinity and femininity among the different gender identities of heterosexual metropolitan men. The results of the F-test, including means, F-value, and $\mathrm{p}$ value for Hypothesis 1 are presented in Table 3.

Table 3 Masculinity and Femininity Means Comparisons.

\begin{tabular}{|c|c|c|c|c|c|c|}
\hline \multirow{2}{*}{ GI } & \multirow{2}{*}{$\mathbf{n}$} & \multirow{2}{*}{$\%$} & \multicolumn{2}{|c|}{ Masculinity } & \multicolumn{2}{|c|}{ Femininity } \\
\hline & & & Mean & S.D. & Mean & S.D. \\
\hline $\mathrm{M}$ & 16 & 6.08 & 5.30 & .787 & 4.53 & 1.060 \\
\hline $\mathrm{F}$ & 103 & 39.16 & 4.67 & .815 & 4.97 & .575 \\
\hline $\mathrm{A}$ & 35 & 13.31 & 5.49 & .831 & 5.18 & .925 \\
\hline $\mathrm{U}$ & 109 & 41.44 & 4.43 & .808 & 4.15 & .761 \\
\hline Total & 263 & 100 & 4.72 & .888 & 4.63 & .850 \\
\hline \multicolumn{3}{|l|}{ F Value } & \multicolumn{2}{|c|}{18.008} & \multicolumn{2}{|c|}{28.788} \\
\hline \multicolumn{3}{|l|}{ Significant } & \multicolumn{2}{|c|}{0.000} & \multicolumn{2}{|c|}{0.000} \\
\hline
\end{tabular}

Hypothesis 2: Significant differences will exist between the different gender identities of heterosexual metropolitan men when measured by appearance-related variables i.e. a) self monitoring, b) status consumption, c) fashion consciousness, d) cloth concern, and e) body self-relation

Table 3 indicates that there are significant differences between the different gender identities of heterosexual metropolitan men when measured using a) self monitoring, b) status consumption, c) fashion consciousness, d) cloth concern, and e) body self-relation variables. The results of the F-test, including means, F-value, and $\mathrm{p}$ value for Hypothesis 2 are presented in Table 4.

Table 4 APVs Means Comparisons

\begin{tabular}{|c|c|c|c|c|c|c|c|c|c|c|c|c|c|c|}
\hline \multirow{2}{*}{ Gender Identity } & \multicolumn{2}{|c|}{ SEMOAB } & \multicolumn{2}{|c|}{ SEMOSEN } & \multicolumn{2}{|c|}{ STATUS } & \multicolumn{2}{|c|}{ FASCN } & \multicolumn{2}{|c|}{ CLCON } & \multicolumn{2}{|c|}{ APPEV } & \multicolumn{2}{|c|}{ APPOR } \\
\hline & Mean & S.D. & Mean & S.D. & Mean & S.D. & Mean & S.D. & Mean & S.D. & Mean & S.D. & Mean & S.D. \\
\hline Masculine (M) & 4.92 & .961 & 4.48 & 1.247 & 3.58 & 1.474 & 3.50 & 1.275 & 4.04 & 1.224 & 4.15 & 1.311 & 4.31 & .762 \\
\hline Feminine $(\mathrm{F})$ & 5.18 & .770 & 5.17 & .821 & 4.33 & 1.301 & 4.48 & 1.451 & 4.64 & 1.056 & 4.68 & 1.091 & 5.13 & .920 \\
\hline Androgynous (A) & 5.16 & .947 & 5.24 & 1.112 & 4.06 & 1.450 & 4.56 & 1.252 & 4.64 & 1.027 & 4.85 & .974 & 4.77 & .979 \\
\hline Undifferentiated (U) & 4.78 & .763 & 4.74 & .698 & 3.85 & 1.277 & 3.97 & 1.306 & 4.30 & .910 & 4.11 & 1.051 & 4.57 & .946 \\
\hline Total & 5.00 & .823 & 4.96 & .881 & 4.05 & 1.338 & 4.22 & 1.385 & 4.46 & 1.018 & 4.43 & 1.112 & 4.80 & .968 \\
\hline F Value & \multicolumn{2}{|c|}{5.073} & \multicolumn{2}{|c|}{7.566} & \multicolumn{2}{|c|}{3.109} & \multicolumn{2}{|c|}{4.702} & \multicolumn{2}{|c|}{3.301} & \multicolumn{2}{|c|}{7.293} & \multicolumn{2}{|c|}{8.089} \\
\hline Significance & \multicolumn{2}{|c|}{0.002} & \multicolumn{2}{|c|}{.000} & \multicolumn{2}{|c|}{.027} & \multicolumn{2}{|c|}{.003} & \multicolumn{2}{|c|}{.021} & \multicolumn{2}{|c|}{.000} & \multicolumn{2}{|c|}{.000} \\
\hline
\end{tabular}

To take this further, paired comparison by least significant difference test (LSD) was conducted to examine differences at the specific level. The results indicate that heterosexual metropolitan men who have feminine and androgynous personality traits have higher average scores for all appearance-related variables than heterosexual metropolitan men who have masculine and undifferentiated personality traits. And among feminine and androgynous traits, there is a significant difference in terms of their appearance orientation i.e. feminine traits tend to be more appearance oriented than androgynous traits. The results of the LSD test, including means, mean difference, and $\mathrm{p}$ value are presented in Table 5. 
Table 5 Least Significant Difference Pair Comparisons

\begin{tabular}{|c|c|c|c|c|c|c|}
\hline \multirow{3}{*}{\begin{tabular}{|l} 
APVs \\
SEMOAB
\end{tabular}} & \multicolumn{3}{|c|}{ Metrosexual Gender Identity } & \multirow{2}{*}{$\begin{array}{c}\text { Mean Diff. } \\
-.40\end{array}$} & \multirow{2}{*}{$\begin{array}{c}\text { Std. Error } \\
.111\end{array}$} & \multirow{2}{*}{$\begin{array}{c}\mathbf{p} \\
.000\end{array}$} \\
\hline & $U(4.78)$ & $F$ & 5.18 & & & \\
\hline & & $A$ & 5.16 & -.38 & .156 & .016 \\
\hline \multirow[t]{4}{*}{ SEMOSEN } & \multirow[t]{2}{*}{$M(4.48)$} & $F$ & 5.17 & -.69 & .228 & .003 \\
\hline & & $A$ & 5.24 & -.76 & .256 & .003 \\
\hline & \multirow[t]{2}{*}{$U(4.74)$} & $F$ & 5.17 & -.43 & .117 & .000 \\
\hline & & $A$ & 5.24 & -.50 & .165 & .003 \\
\hline \multirow[t]{2}{*}{ STATUS } & \multirow[t]{2}{*}{$F(4.33)$} & $M$ & 3.58 & -.75 & .355 & .035 \\
\hline & & $U$ & 3.85 & .48 & .182 & .008 \\
\hline \multirow[t]{4}{*}{ FASCN } & \multirow[t]{2}{*}{$M(3.50)$} & $F$ & 4.48 & -.98 & .365 & .007 \\
\hline & & $A$ & 4.56 & -1.06 & .409 & .010 \\
\hline & \multirow[t]{2}{*}{$U(3.97)$} & $F$ & 4.48 & -.51 & .186 & .007 \\
\hline & & $A$ & 4.56 & -.59 & .264 & .028 \\
\hline \multirow[t]{3}{*}{$\overline{C L C O N}$} & \multirow[t]{2}{*}{$M(4.04)$} & $F$ & 4.64 & -.60 & .270 & .030 \\
\hline & & $A$ & 4.64 & -.60 & .303 & .049 \\
\hline & $U(4.30)$ & $F$ & 4.64 & -.34 & .138 & .015 \\
\hline \multirow[t]{3}{*}{ APPEV } & $M(4.15)$ & $A$ & 4.85 & -.70 & .324 & .033 \\
\hline & \multirow[t]{2}{*}{$U(4.11)$} & $F$ & 4.68 & -.57 & .148 & .000 \\
\hline & & $A$ & 4.85 & -.74 & .209 & .000 \\
\hline \multirow[t]{3}{*}{ APPOR } & \multirow[t]{3}{*}{$F(5.13)$} & $M$ & 4.31 & .82 & .250 & .001 \\
\hline & & $A$ & 4.77 & .36 & .182 & .049 \\
\hline & & $U$ & 4.57 & .56 & .128 & .000 \\
\hline
\end{tabular}

\section{DISCUSSION AND IMPLICATION OF FINDINGS}

The term "metrosexual" has been used to describe heterosexual metropolitan men who possess feminine personality traits which focus closely on their appearance. This research is the first empirical study which tries to identify metrosexuals using gender identity constructs. The result is congruence with marketing practice. This empirical study posits that heterosexual metropolitan men can be categorized into four gender identity groups: masculine, feminine, androgynous, and undifferentiated. And heterosexual metropolitan men who possess high scores for femininity, which characterizes feminine and androgynous behavior, tend to put a lot of emphasis on all appearance-related variables. They can be described as metrosexuals. With respect to Thai metrosexuals, this study demonstrates that self monitoring, body self-relation, fashion consciousness, cloth concern and status consumption can be ranked in this order of importance in metrosexual decision making.

\section{LIMITATIONS AND FURTHER RESEARCH}

Our sample was relatively large, making the results prone to generalization problems, this research has some limitations. This study pertains to the selectivity of the sample, which is from one cultural context, Thailand, which is a high-collectivism culture. As a result, consumers by nature rate relatively highly in terms of their femininity. Although the results derived from this sample provide useful knowledge pertaining to metropolitan men, who represent an emerging market for fashion products, these results are not intended to be universally generalized to all metropolitan men worldwide. Further study needs to conduct in other context, especially in individualistic culture.

\section{ACKNOWLEDGEMENTS}

Research for this article was supported by a grant from Office of the Higher Education Commission and Thailand Research Fund under contract number MRG5180128 and Suan Dusit Rajabhat University 


\section{REFERENCES}

1. Bakewell, C., Mitchell, V.-W., \& Rothwell, M. (2006). UK generation y male fashion consciousness. Journal of Fashion Marketing and Management, 10(2), 169-180.

2. Bem, S. L. (1974). The measurement of psychological androgyny. Journal of Consulting and Clinical Psychology, 42(2), 155-162.

3. Bem, S. L. (1981a). Bem sex-role inventory: Consulting Psychological Press.

4. Bem, S. L. (1981b). Gender schema theory: A cognitive account of sex typing. Psychological Review, 88(4), 354-364.

5. Blazina, C., \& Watkins, J., C. Edward. (2000). Separation/individuation, parental attachment, and male gender role conflict: Attitudes toward the feminine and the fragile masculine self. Psychology of Men and Masculinity, 1(2), 126-132.

6. Dittmar, H., Beattie, J., \& Friese, S. (1994). Gender identity and material symbols: Objects and decision considerations in impulse purchases. Journal of Economic Psychology, 16(3), 491-511.

7. Eastman, J. K., Goldsmith, R. E., \& Flynn, L. R. (1999). Status consumption in consumer behavior: Scale development and validation. Journal of Marketing Theory and Practice, 7(3), 41-52.

8. Gill, S., Stockard, J., Johnson, M., \& Williams, S. (1987). Measuring gender differences: The expressive dimension and critique of androgyny scales. Sex Roles, 17(7/8), 375-400.

9. Gould, S. (1993). Assessing self-concept discrepancy in consumer behavior: The joint effect of private selfconsciousness and self-monitoring. Advances in Consumer Research, 20, 419-424.

10. Holt, D. B., \& Thompson, C. J. (2004). Man-of-action heroes: The pursuit of heroic masculinity in everyday consumption. Journal of Consumer Research, 31(2), 425-440.

11. Katz, J., \& Farrow, S. (2000). Heterosexual adjustment among women and men with non-traditional gender identities: Testing predictions from self-verification theory. Social Behavior and Personality: An International Journal, 28(6), 613-620.

12. Miller, L. R., Bilimoria, R. N., \& N., P. (2000). Do women want 'new men'? Cultural influences on sex-role stereotypes. Psychology, Evolution \& Gender, 2(2), 127-150.

13. Mitchell, V.-W., \& Walsh, G. (2004). Gender differences in German consumer decision-making styles. Journal of Consumer Behaviour, 3(4), 331-346.

14. Nam, J., Hamlin, R., Gam, H. J., Kang, J. H., Kim, J., Kumphai, P., et al. (2006). The fashion-conscious behaviours of mature female consumers. International Journal of Consumer Studies, 1-9.

15. Netemeyer, R. G., Burton, S., \& Lichtenstein, D. R. (1995). Trait aspects of vanity: Measurement and relevance to consumer behavior. Journal of Consumer Research, 21(March), 612-626.

16. O'Cass, A. (2000). A psychometric evaluation of a revised version of the Lennox and Wolfe revised selfmonitoring scale. Psychology \& Marketing, 17(5), 397-419.

17. Palan, K. M. (2001). Gender identity in consumer behavior research: A literature review and research agenda. Academy of Marketing Science Review, 2001(10).

18. Simpson, Mark. (November 15, 1994). "Here come the mirror men". The Independent (London), p. 22.

19. Shim, S., \& Gehrt, K. C. (1996). Hispanic and Native American adolescents: An exploratory study of their approach to shopping. Journal of Retailing, 72(3), 307-324.

20. Snyder, M. (1974). Self-monitoring of expressive behavior. Journal of Personality and Social Psychology, 30, 526-537.

21. Spence, J. T. (1984). Masculinity, femininity, and gender-related traits: A conceptual analysis and critique of current research. Progress in Experimental Personality Research, 13, 1-97.

22. Spence, J. T. (2006). Do the BSRI and PAQ measure the same or different concepts? Psychology of Women Quarterly, 15(1), 141-165.

23. Walsh, G., Mitchell, V. W., \& Thuran, T. H. (2001). German consumer decision-making styles. The Journal of Consumer Affairs, 35, 73-96.

24. Wells, W. D., \& Tigert, D. J. (1971). Activities, interests, opinions. Journal of Advertising Research, 11(August), 27-35. 
NOTES 